\title{
Eqüidade e reformas na saúde nos anos 90
}

\author{
Equity and health reforms in the 1990s
}

Amélia Cohn 1,2

Paulo Eduardo Mangeon Elias 1,2

\footnotetext{
1 Departamento de Medicina Preventiva, Faculdade de Medicina, Universidade de São Paulo. Av. Dr. Arnaldo 455, São Paulo, SP 01246-903, Brasil. amelcohn@usp.br pemelias@usp.br

2 Centro de Estudos de Cultura Contemporânea. Rua Airosa Galvão 64, São Paulo, SP 05002-070, Brasil.
}

\begin{abstract}
The first section of this article analyzes current issues on the agenda for research and debate in Brazilian Health Reform, from the perspective of social inclusion and exclusion. In light of the issues discussed initially, the second section analyzes the experience involving partnership between the public sector (the University Hospital at the School of Medicine, University of São Paulo) and the Supplementary Health Care System (SSAM). The authors' hypothesis focuses on the depletion of the original set of ideals underlying the Brazilian Health Reform movement after the gains it obtained in the 1988 Constitution and in the face of the country's new reality, with the resulting need to recuperate the emphasis on the political dimension in health studies, highlighting the issue of constructing the identities of social stakeholders. Based on this initial approach, the authors proceed to analyze this partnership, demonstrating the existence of a "double waiting line" - users of the Unified National Health System, or SUS, and those of the SSAM - which does not imply discrimination per se in access to technology, but reproduces within the University Hospital the forms of discrimination that already exist in Brazilian society.
\end{abstract}

Key words State Reform; Health Care Reform; Health Services; Social Discrimination

Resumo O presente artigo analisa na primeira seção questões atuais colocadas para a agenda de estudos e debates sobre a Reforma Sanitária Brasileira da perspectiva da inclusão e da exclusão sociais. E numa segunda seção, à luz daquelas questões inicialmente discutidas, analisa uma experiência de parceria entre o setor público estatal (o Hospital das Clínicas - HC, Faculdade de Medicina, Universidade de São Paulo) e o Sistema Supletivo de Assistência Médica (SSAM). A tese apresentada é a do esgotamento do ideário original da Reforma Sanitária Brasileira, após a conquista do movimento consagrado na Constituição de 1988, e frente à nova realidade do país, com a conseqüente necessidade de se resgatar a ênfase na dimensão política nos estudos sobre saúde, colocando em destaque a questão da construção de identidades dos sujeitos sociais. A partir dela é analisada a experiência daquela parceria, mostrando como a existência da "dupla fila" - a dos usuários SUS e a dos usuários do SSAM - não implica discriminações no acesso à tecnologia, mas reproduz no interior do HC as discriminações já existentes na sociedade.

Palavras-chave Reforma do Estado; Reforma Sanitária; Serviços de Saúde; Discriminação Social 
O tema das reformas na saúde, da ótica da democratização política e institucional do setor, vem sendo bastante trabalhado na literatura brasileira, dando seqüência ao fluxo da produção intelectual atinente à Reforma Sanitária no Brasil. Essa produção, no entanto, vem sendo marcada por pelo menos dois traços: (a) por um relativo desprezo pela questão da articulação entre política, saúde e democracia; e (b) por um relativo esvaziamento das questões atinentes à descentralização, à reforma do Estado e às políticas de saúde no que diz respeito às suas potencialidades e constrangimentos na implementação dos preceitos constitucionais do SUS. No primeiro caso, parte-se da desigualdade para a matriz da eqüidade, e por esta via aos preceitos constitucionais do arcabouço institucional do SUS e o ambiente da consolidação democrática no país. No segundo, privilegia-se a ênfase em dimensões como a do gerenciamento, a da regionalização, e a da normatização, planejamento e avaliação dos serviços de saúde, em detrimento da dimensão da desigualdade enquanto um fenômeno que envolve exatamente a articulação entre política, saúde e democracia.

A hipótese que orienta a análise aqui presente é que isso ocorre dado o esgotamento das propostas originais da Reforma Sanitária Brasileira, inscritas no texto constitucional de 1988, quando suas conquistas são institucionalizadas, e que a partir de então, sobretudo de meados dos anos 90, o que se verifica é a ênfase nos aspectos pragmáticos da regulamentação e implementação do SUS, com destaque nas suas dimensões técnicas (gerência, programação e avaliação, dentre outras).

Isso no entanto não ocorre isoladamente, mas coincide com o processo de tecnificação das políticas sociais a partir de 1994, com o governo Fernando Henrique Cardoso, reforçando assim a tendência de se reduzir a questão da justiça social e da eqüidade e democratização da saúde a parâmetros meramente quantitativos (de custo/efetividade, cobertura, avaliação, perfil do gasto, entre outros), conforme Cohn (2000). Mas se essa dimensão não pode ser desconhecida, até porque diz respeito à gerência da alocação dos recursos públicos, por outro lado tem que se ter clareza de que ela não substitui a dimensão propriamente política das reformas que se vêm promovendo no setor.

Daí porque a perspectiva que orienta este texto ser a da necessidade de se promover, ao se tratar da questão da saúde e democracia, o resgate da dimensão política aí presente. Em conseqüência, a necessidade de se sair da matriz da pobreza - e da sua naturalização - e pas- sar para a matriz da desigualdade social, embora esta também já venha sofrendo entre nós um processo de naturalização, como aponta Henriques (2000).

Com essas questões em mente, o presente texto será dividido em duas sessões: a primeira voltada para questões de ordem mais geral relativas à dimensão da necessidade do resgate da política ao se tratar de saúde e democracia; e a segunda dedicada à análise das implicações, para a desigualdade, da gestão de um hospital público estatal que se propõe a dispor parte de seus leitos para o mercado.

\section{Saúde, democracia e política na trajetória da Reforma Sanitária Brasileira}

A concepção que articula saúde, democracia e política no ideário que dá suporte à Reforma Sanitária Brasileira durante as décadas de 70 , 80 e parte dos anos 90 é a do Estado desenvolvimentista, conforme Sallum (1996). Daí porque a estratégia política adotada - de ocupação de espaços no interior do aparelho de Estado uma vez que se concebia, por meio da saúde, promover radicais transformações sociais, retomando-se uma relação imediata entre política e democracia na saúde.

Em decorrência, tem-se como eixos temáticos então predominantes: controle social e participação social; descentralização e poder local; estatal versus privado; universalidade e integralidade da atenção à saúde. É o momento, por exemplo, de numerosos estudos sobre a universalidade excludente, dentre eles o de Faveret Filho \& Oliveira (1989), o poder local como o locus privilegiado da prática democrática. Não é o objetivo aqui resgatar o acervo da produção científica sobre esses temas dada a estrutura do presente texto. No entanto, talvez seja de utilidade tão somente mencionar alguns desses trabalhos que retomam aquelas questões de forma mais reflexiva, dentre eles os de Elias (1997), sobre a reforma sanitária e Nascimento (2001), sobre a descentralização do sistema de saúde, bem como os de Souza (2001), federalismo e gasto social, e de Arretche (1996), descentralização e eficiência nas políticas públicas. Já sobre o tema das reformas do setor da saúde no Brasil e na América Latina, destacamse os trabalhos de Almeida (1999) e de Fleury (2000); registre-se no entanto a tendência de nos estudos sobre o sistema de saúde prevalecer, mesmo nesses trabalhos, a perspectiva do arranjo institucional do contexto das reformas e do próprio sistema de saúde, detendo-se por- 
tanto nos aspectos institucionais da dimensão política em detrimento daquela aqui tratada.

Nesse sentido, importa que de fato, e coerente com o ideário de origem da proposta reformista da saúde, o tema privilegiado sob a égide ainda da concepção desenvolvimentista recai sobre o "controle social”. Concebido como "social” e não "público", o que já traz implicações, a atenção dos pesquisadores e dos líderes do movimento sanitário é voltada para os Conselhos de Saúde, sem dúvida conquista das mais significativas no arcabouço institucional do SUS.

O controle social assim concebido traduz a preocupação central que inspirou a reforma sanitária no país: a ênfase na legitimação das decisões políticas setoriais em contraposição à ênfase no exercício, através desse espaço, do controle público. Em resumo, parceira da luta pela democratização das instituições políticas no país, a participação social por meio dos Conselhos de Saúde menos do que um espaço e um mecanismo de controle público, isto é, de um instrumento de participação social que trouxesse para as instâncias deliberativas os interesses do bem comum, acabam sendo confundidos como espaços de representação de interesses comuns dos segmentos organizados da sociedade que neles tivessem assento.

A pressuposição aí presente é a da existência de uma necessária coincidência entre ambos - interesses do bem comum e interesses comuns. Assim, o interesse de cada grupo ou segmento social coincidiria com os dos demais grupos e/ou segmentos sociais. No entanto, a questão não é a da coincidência de interesses entre ambos, mas sim que cada cidadão tenha o direito de ter seus interesses igualmente considerados no processo de tomada de decisão. Daí a igualdade política não poder ser justificada em termos normativos, tão somente pela noção de bem comum, mas por determinadas coincidências entre distintos interesses particulares que constituiriam assim o interesse comum, agora representando o bem comum.

Não é sem sentido, portanto, o predomínio nesse período de determinados temas e teses presentes na produção especializada: descentralização e poder local, sempre com o pressuposto da existência de uma relação positiva entre ambos, atribuindo-se extrema importância ao executivo, o que é coerente com a concepção fundadora de estado desenvolvimentista; relação público/privado, entendida como estatal versus privado, residindo a virtude no estatal (e não no público); estatal associado à descentralização, com ênfase na vontade política do executivo, dentre outros.
O final dos anos 90 e o início do novo século constituem, no entanto, um novo contexto, em que mudam o cenário e os personagens envolvidos com as reformas na saúde. Em primeiro lugar, o panorama social consolida-se na tendência da desigualdade. De fato, um dos consensos mais estabelecidos na intelectualidade brasileira é de que a pobreza no Brasil não aumentou e de que existe uma relativa estabilidade da desigualdade de renda no país, e que a causa da pobreza está exatamente nessa desigualdade. No entanto, não há consenso quanto à natureza da diferença entre pobreza $\mathrm{e}$ desigualdade, dadas exatamente as diferentes perspectivas de análise sobre o que caracteriza a pobreza, e em conseqüência a desigualdade social: dentre eles renda, consumo de serviços básicos, qualidade de vida, grau de satisfação das necessidades sociais básicas. Mas sobretudo não existe consenso quanto às implicações para as desigualdades sociais das políticas públicas enquanto meios de regulação social materializando determinados contratos sociais estabelecidos.

Lavinas (2000), por exemplo, tratando da questão das políticas sociais compensatórias e distributivas, refaz a trajetória das diferentes concepções e modelos de Estado de bem-estar social, e aponta que ao contrário dos modelos bismarkiano e beveredgiano, hoje prevalece o modelo de direitos de cidadania desvinculados da condição dos indivíduos no mercado de trabalho, não mais coincidindo o direito de proteção social com o direito de cidadania, e prevalecendo agora a relação entre benefícios sociais e responsabilidades cívicas. O que a autora enfatiza é exatamente que através dessa mudança move-se do campo dos direitos para o da responsabilidade individual.

E se esse processo abre flanco para o mercado, ele também acena para a possibilidade de emancipação social, e portanto para a política. Ao mesmo tempo, ele não exime a presença do Estado no seu papel de exercer a regulação das relações sociais, promovendo certo grau de igualdade (no que diz respeito à satisfação das necessidades sociais básicas), e assim contrabalançando as desigualdades geradas pelo mercado.

No entanto, se esse novo modelo de regulação social que enfatiza a vinculação dos direitos sociais ao mercado reivindica a autonomia dos sujeitos sociais, uma vez que é essa condição que os fortalece diante do próprio mercado, fazendo valer de forma autônoma e emancipada sua condição de consumidor, não é esta a realidade dos países com enorme desigualdade social, como é o caso da sociedade brasilei- 
ra. Os personagens hoje em cena não são mais sujeitos sociais com diferentes gradientes de posição no mercado, mas sim aqueles que estão incluídos e aqueles que estão excluídos do mercado, tal como apontado por Fiori (1993).

E isso num contexto de crise dos padrões de regulação social capitalista gerando inclusão e exclusão via mercado e via padrões de gestão controlada da desigualdade e da exclusão sociais. Resta então indagar sobre quais as identidades desses atores sociais. E isso quando Offe (1989), já nos anos 80, apontava para o fato de que o trabalhador só se transforma em trabalhador assalariado quando se torna cidadão, uma vez que na ausência de direitos políticos e sociais o potencial produtivo da força de trabalho, as formas de vida das quais depende a reprodução e as disposições normativas para o trabalho tendem a se desestruturar, perdendo-se assim os parâmetros e as matrizes de sua identidade e de seu estatuto de trabalhador. Em conseqüência, na ausência desse padrão de regulação e do próprio trabalho, o trabalhador ganha um novo estatuto - o de pobre, desocupado, carente, ocioso, vadio...

Assim, pobreza e desigualdade não significam, portanto, somente precariedade das condições de vida, mas também a ausência de determinados fatores que permitam a construção de parâmetros materiais e simbólicos de semelhança, identificação e reconhecimento. Em conseqüência portanto desse mercado de trabalho sem regras, cria-se o ideário da aleatoriedade dos acontecimentos, tidos como naturais, que se confundem com a fortuna de cada um. Assim, um dos problemas centrais da exclusão social no Brasil diz respeito exatamente à "ausência de direitos como uma medida de equivalência (mesmo para os trabalhadores assalariados) que articula diferenças pela mediação de referências comuns, que fundam modos de mútuo e auto-reconhecimento", conforme Telles (1999:145).

Daí por que se resgatar Sen (2000), para se pensar a questão da desigualdade no Brasil na nova conjuntura atual que criva a sociedade entre excluídos/incluídos, ou globalizáveis/não globalizáveis, segundo Fiori (1993). O essencial neste caso não reside na classificação dos segmentos sociais enquanto aqueles estatutos, mas sim a partir das raízes históricas que determinam essa condição atual, quais sejam:

(1) a ausência em nossa história da condição da cidadania enquanto estatuto de auto determinação e de autonomia dos sujeitos sociais, independentemente de sua situação no gradiente socioeconômico em que se encontram. Ao contrário, nossa herança histórica consiste na condição de cidadão enquanto consumidor do Estado, e portanto enquanto indivíduo parasita do Estado: é o cidadão dependente, e nessa condição de indivíduos pobres que para sua sobrevivência dependem dos serviços providos pelo Estado. Veja-se, neste caso, a freqüência com que se utiliza na comunidade dos estudiosos e profissionais da saúde a expressão "SUS dependente".

(2) a ausência da cidadania como acesso a determinados direitos universais, e portanto enquanto medida de equivalência contraposta à diferenciação social.

(3) em conseqüência, a necessidade de se distinguir a nova da velha pobreza: não mais distinguindo-as enquanto sua natureza estrutural e conjuntural, como anteriormente, mas enquanto suas novas e velhas estruturas, dada a nova conjuntura do desenvolvimento na era global.

(4) portanto, não mais se pensar a sociedade brasileira em termos de um dualismo estrutural, mas enquanto uma sociedade fraturada entre excluídos e incluídos, e articulada internamente a partir de um projeto de desenvolvimento não enquanto país economicamente emergente, mas enquanto um país que assume um modelo passivo de desenvolvimento.

(5) em conseqüência, tem-se um processo de naturalização da pobreza, da exclusão social e portanto das desigualdades sociais, que acaba por reger as propostas de reforma do Estado e de gestão dos serviços de saúde.

Diante dessa complexidade com que se revestem as desigualdades sociais hoje, como se pensar a própria desigualdade e seu reverso - a eqüidade - em saúde?

Uma das possibilidades seria levar em conta o que Rawls (1993) propõe enquanto a associação entre os bens primários que as pessoas possuem e as respectivas características pessoais ou grupais relevantes que governam a sua conversão na capacidade de as pessoas promoverem seus objetivos. A isso o autor associa o conceito de funcionamentos, que podem variar entre aqueles elementares (por exemplo, nutrição adequada e estar livre da ameaça das doenças evitáveis) a estados complexos, como poder participar da vida da comunidade sem sentir vergonha, e ter respeito próprio. Àquele, por sua vez, está associado o conceito de capacida$d e$, que corresponderia a um tipo de liberdade substantiva de a pessoa poder realizar combinações alternativas de funcionamentos, vale dizer, de optar por estilos de vida diversos.

No caso da saúde, isso implicaria a necessidade de se escolher espaços focais para a realização de diagnósticos, formulação e avaliação 
de políticas e programas de saúde, com a seleção de alguns funcionamentos detectados como significativos, especificados nesse espaço focal, e que a própria relação de dominância que aí se estabelece conduz a uma ordenação parcial de estados de coisas alternativos. Seria o caso, por exemplo, de se distinguir e especificar necessidade, demanda e direitos em saúde numa realidade social heterogênea e opaca, remetendo-se aqui à análise de Fitoussi \& Rosanvallon (1996), como é o caso brasileiro, ou mesmo no interior do espaço institucional de um hospital.

Tal esforço remete não só à necessidade de se pensar a superação da dicotomia entre as dimensões política e técnica, hoje ainda presente na grande maioria das análises sobre a questão da saúde no país, mas a partir daí a própria necessidade de superação da concepção da existência no Brasil de um sistema dual de proteção social, com distintas lógicas de articulação com o sistema econômico: um subsistema securitário, baseado na lógica contributiva, e portanto em tese na captação de poupanças individuais, e um subsistema assistencialista, baseado no financiamento com recursos orçamentários, e portanto em tese redistributivista.

A partir daí o que está em jogo é a necessidade de se buscar novas formas de articulação entre essas dimensões, potencializando assim novas formas de relação entre Estado e sociedade que promovam a autonomia dos sujeitos sociais versus a lógica hoje predominante nas políticas sociais que vêm sendo implementadas, e que reforçam a redução desses sujeitos sociais à condição de cidadãos consumidores dos serviços providos pelo Estado, e não os promovem a sujeitos sociais autônomos para praticar suas escolhas.

Nesse caso, o que se propõe é que as análises sobre as políticas de saúde - e as propostas daí decorrentes - tomem a idéia de identidade desses sujeitos sociais como central, bem como o ethos da diferença da perspectiva da promoção da igualdade segundo a diferença, tal como propõe Sen (1993:333) em seus trabalhos, e que explicita em afirmações tais como: "uma avaliação informada e inteligente tanto das vidas a que somos forçados como das vidas que poderíamos escolher mediante reformas sociais é o primeiro passo para o enfrentamento daquele desafio". O desafio em questão reside no fato de o desenvolvimento humano não poder ser plenamente compreendido sem se levar em conta que ele só pode ser avaliado a partir de nossos valores humanos mais prezados.

Diante desse novo desafio - o de se pensar as políticas sociais e de saúde - na atual con- juntura de uma sociedade fraturada em que os projetos sociais encontram seus limites no contexto da globalização, e de uma realidade na área da saúde em que o projeto da Reforma Sanitária encontra-se esgotado enquanto formulação de uma proposta concreta - o SUS acolhida pela nova constitucionalidade, e articulada a um projeto político também já esgotado - a construção da institucionalidade democrática no país, o que se verifica é o próprio esgotamento nas análises, nos estudos e nas propostas setoriais formuladas pela mesma comunidade científica autora daquele ideário. Em conseqüência, o que se verifica é uma produção científica dedicada sobretudo a um projeto de avaliação do SUS a partir dos mesmos parâmetros que fundaram as propostas anteriores, mas agora numa realidade distinta. Daí porque a ênfase dessa literatura mais recente na temática da avaliação a partir de parâmetros ditados por modelos normativos, gerenciais e administrativos, em detrimento das dimensões políticas e sociais propriamente ditas.

\section{Novas formas de gestão de serviços públicos estatais de saúde: a exclusão social}

O propósito desta sessão é analisar a experiência do Hospital das Clínicas (HC) da Universidade de São Paulo, a partir da participação do sistema privado de atendimento médico nessa instituição estatal, originalmente criada somente para o atendimento público.

O Hospital das Clínicas é um hospital universitário vinculado à Faculdade de Medicina da Universidade de São Paulo (FMUSP). Nessa condição, realiza atividades nos campos da pesquisa, ensino e assistência médica, situando-se como instituição de ponta nesses campos de atuação, e como instituição de referência na área da saúde em tecnologia de alta complexidade. A sua natureza jurídica é a de uma autarquia vinculada à Secretaria de Saúde do Estado de São Paulo. Nessa condição, sua fonte de financiamento é constituída por recursos orçamentários estaduais e por recursos advindos do SUS por pagamento de serviços prestados.

Por conta dessa estreita relação com o setor público e apesar de sua condição de autarquia, o HC acaba por padecer dos mesmos males da crise que atinge o sistema de saúde brasileiro baixa remuneração dos serviços prestados ao SUS, expansão da demanda por seus serviços decorrente da inexistência de uma política de regionalização da atenção à saúde no Estado de São Paulo, baixos salários pagos ao seu cor- 
po de funcionários, sucessivos cortes orçamentários.

Por outro lado, em 1986 é criada pela Associação dos Antigos Alunos da FMUSP a Fundação Faculdade de Medicina (FFM), de direito privado e sem fins lucrativos, concebida como um mecanismo que imprima maior agilidade $\mathrm{e}$ eficiência à gestão administrativa e financeira aos serviços prestados pela FMUSP e pelo próprio HC. Tendo em vista esses objetivos, cabe à FFM captar recursos extra orçamentários para ambas as instituições e dispor de mecanismos de gestão para a racionalização na prestação dos serviços por elas prestados, basicamente entendidos como mecanismos de gerenciamento dos recursos humanos e materiais utilizados, e que não sejam engessados pela condição de ser uma instituição estatal da administração direta.

Com esses objetivos, a relação da FFM com o HC está estabelecida sob a forma de um convênio em que se destacam as seguintes obrigações: por parte do HC, permitir a utilização de suas instalações, seus equipamentos e seus materiais; e por parte da FFM, fornecer apoio administrativo, financeiro e de valorização dos recursos humanos envolvidos. Em virtude do teto estabelecido pelo nível federal para a remuneração de serviços prestados ao SUS, estabelece-se a insuficiência dos recursos advindos desta fonte, pondo em risco a continuidade da estratégia de modernização do HC para o cumprimento de suas funções; a partir de 1995 é instituído um convênio com a FFM como um mecanismo alternativo de captação de recursos de apoio ao HC. Essa captação está fundada em convênios e acordos com terceiros, sejam eles pessoas físicas ou jurídicas, incorporando assim a prestação de serviços ao Sistema Supletivo de Assistência Médica (SSAM), que passa então a constituir fonte adicional de recursos para a instituição. É portanto essa articulação dos sistemas SUS e Supletivo que resulta em fonte alternativa de financiamento do HC, caracterizado como um "subsídio cruzado".

A adoção desse novo modelo está fundamentada na compreensão de que ele capitaliza o HC, possibilitando investimentos de modernização da produção dos serviços hospitalares em geral, além de possibilitar a criação de um superávit de recursos que se traduziria num aumento do atendimento aos pacientes do SUS, neste caso financiado com os recursos extras captados junto ao SSAM.

Por essa lógica, a FFM passa a gerenciar para o HC tanto os recursos provenientes do SUS quanto do SSAM. É com essa finalidade que foram criados os Centros de Gerenciamento (CG), responsáveis por implementar a descentralização na gestão do HC, uma vez que têm autonomia na gerência dos respectivos recursos orçamentários repassados a eles a partir da captação feita junto ao SUS e ao SSAM. Na atualidade existem cerca de 60 CGs, que correspondem a departamentos ou divisões do HC, e na sua maioria são dirigidos por professores titulares da FMUSP, o que faz com que no geral cada CG corresponda a uma unidade do HC, o que por sua vez guarda relação com uma disciplina ministrada pela faculdade.

Uma vez rateados pela FFM, a partir de critérios estabelecidos pelo Conselho Deliberativo do HC, os recursos arrecadados pelo faturamento dos serviços prestados aos pacientes do SUS e a aqueles particulares e conveniados vinculados a Planos de Saúde, cada CG os aloca segundo critérios próprios, embora no geral sejam destinados à complementação salarial do respectivo quadro de pessoal, à contratação de pessoal, e à aquisição de insumos e equipamentos. Por sua vez, os dados relativos à produção de serviços e ao faturamento apontam para a tendência de aumento dos serviços vinculados ao SSAM, e conseqüentemente ao aumento de sua parcela no faturamento global do HC, ocupando portanto lugar de progressiva importância no interior do processo de modernização administrativa do HC. À guisa de exemplo, em 1997 o SSAM era responsável por 2,17\% das internações e por $0,34 \%$ dos procedimentos ambulatoriais, que foram responsáveis respectivamente por $9,75 \%$ e $6,31 \%$ do faturamento por serviços prestados, dados estes que correspondem, em 1999, a 4,61\% das internações e $0,60 \%$ dos procedimentos ambulatoriais, correspondendo respectivamente por $14,37 \%$ e $6,31 \%$ do faturamento do HC.

Diante dessa realidade, resta se indagar sobre se os benefícios advindos dos "benefícios cruzados" daí decorrentes não estariam contrariando a lógica da universalidade do acesso à assistência médica que deve reger a gestão das instituições públicas estatais. De fato, o que se verifica é que do ponto de vista do acesso à tecnologia propriamente dita no atendimento aos usuários, não se constata diferenças entre o público SUS e o público do SSAM, no mais das vezes distinguindo-se somente no tempo de espera para a realização de exames e de determinados procedimentos médicos. No entanto, o que marca a distinção entre ambos os públicos de usuários é a reprodução no âmbito do espaço hospitalar do apartheid social existente fora de suas paredes.

É pois na dimensão propriamente social da divisão do espaço físico que as discriminações 
sociais emergem: elas se manifestam no desconforto de os usuários do SSAM partilharem as mesmas salas de espera com os usuários SUS. Nesse sentido, o "subsídio cruzado" que beneficiaria a estes por possibilitar a modernização tecnológica do HC esbarra na reafirmação das discriminações sociais presentes em nossa sociedade.

Portanto, a questão tão debatida entre os estudiosos das políticas de saúde de se a "dupla fila" ou a "dupla porta" é um fenômeno que em si fere ou não os princípios do SUS acaba não se revelando tão simples assim. O que a experiência do HC ilustra é que, do ponto de vista do acesso ao atendimento médico propriamente dito, ela não apresenta discriminações entre usuário SUS e usuário SSAM. O que ela ilustra é a discriminação social no que diz respeito a partilhar os espaços, seja nos casos de uma incômoda convivência entre pobres e não-pobres (usuário SUS e usuário SSAM), seja na discriminação quando da partilha de espaços mais privativos (os quartos) em que os pobres são condenados a conviver no mesmo espaço com até quatro pessoas, enquanto os quartos dos não-pobres são partilhados por somente até duas pessoas.

Dessa forma, a separação física do atendimento entre os dois tipos de usuários não afeta a qualidade técnica do atendimento, mas fundamentalmente a organização do processo de trabalho. Tem-se, com isso, que enquanto a recepção do usuário SSAM é feita na própria sala de consulta, reforçando a sua autonomia dada a própria autonomia do profissional, no caso do usuário SUS essa autonomia lhe é negada, sendo ele submetido a uma organização do processo de trabalho muito mais fracionada, tendo seu início no balcão, passando pela sala de triagem, pela própria triagem, até finalmente chegar à consulta. Assim, os tempos de espera para marcação e realização dos exames são distintos, como também é distinto o grau de autonomia dos usuários: no caso do usuário SUS as exigências da racionalidade do funcionamento do HC lhe são impostas como algo natural e já dado, uma vez que se trata de um serviço público estatal voltado para o atendimento de uma demanda crescente que pressiona constantemente a instituição. No caso do usuário SSAM, ele é tratado como um consumidor do mercado, e que como tal suas preferências têm de ser respeitadas já que se trata, neste caso, de a instituição competir com outros serviços privados.

Assim é que em algumas situações enquanto num caso faltam leitos, no outro sobram leitos disponíveis para o mercado. Enquanto num caso os funcionários trabalham com uma demanda sem fim, no outro a demanda é controlada pelas próprias regras do mercado. Enquanto num caso o usuário é carente - assim entendido e tratado pela instituição - no outro ele é um consumidor autônomo que tem de ser disputado pelo Hospital junto a seus concorrentes. Em decorrência, o mesmo quadro de funcionários é obrigado a trabalhar em situações absolutamente distintas, e a adaptar-se às clientelas usuário SUS/usuário SSAM, sofrendo pressões distintas de ambas. Essas distinções, no entanto, não residem em discriminações de acesso à tecnologia disponível num complexo hospitalar que é referência nacional em termos da qualidade tecnológica de atendimento, mas sim na discriminação que é estabelecida pela condição e situação dos sujeitos sociais em termos do mercado - pobres sem acesso ao mercado e não-pobres com acesso ao mercado. E ao que tudo indica essa discriminação só não atinge um acesso discricionário à tecnologia pelo fato de o HC ser um hospital de ensino, e como tal dispor da utilização da tecnologia no processo de trabalho para o atendimento aos usuários.

\section{Considerações finais}

A nova proposta de gestão do HC vem ao encontro dos processos de reforma do Estado no país, e em decorrência das políticas de saúde que vêm sendo implementadas. Isso porque, de um lado, é proposta a parceria dos serviços públicos estatais com iniciativas do mercado, levando a uma alteração da relação setor público/setor privado na produção de serviços de saúde. E de outro, porque leva a que os serviços públicos estatais transplantem para o seu interior a tensão da necessidade de buscar uma nova racionalidade pautada pelos parâmetros do mercado, bem como da coexistência de duas clientelas, exigindo a convivência concomitante de distintas lógicas administrativas que passam a ter de buscar pontos de convergência entre situações radicalmente distintas e divergentes.

Assim sendo, essas novas formas de gestão de parcerias que vêm sendo experimentadas na prática, acabam por implicar a ênfase da modalidade de gerência sob a forma de contratos, a introdução de mecanismos de mercado no setor público estatal, e a estabelecer uma vinculação entre pagamento e desempenho, em detrimento da questão mais ampla sobre a inclusão e exclusão social pautada pela dimensão da cidadania e da autonomia dos sujeitos sociais. 
Da mesma forma que se concebe a pobreza enquanto padrões de renda e se enfatiza a dimensão da avaliação dos serviços e dos programas de saúde em termos de sua funcionalidade interna, assim vem sendo pautada a discussão dessa nova agenda da saúde - a relação que vem se estabelecendo a partir desse novo mix na relação dos setores públicos e privados de prestação de serviços de saúde. Daí a proposta de resgate da dimensão política nesta discussão. E a própria experiência do HC reforça a defesa desta tese, uma vez que ela vem de- monstrar que parcerias dessa natureza demandam mais do que a discussão de se instaurar uma "dupla porta" ou uma "dupla fila" nos serviços públicos estatais. O que ela exige é uma discussão da dimensão social e política dessas novas modalidades de gestão, que ultrapasse os limites do acesso aos serviços de saúde por parte dos distintos segmentos sociais de renda, contemplando agora a dimensão da reprodução, segundo suas práticas institucionais e de gestão, da própria desigualdade social em termos de exclusão e inclusão social.

\section{Referências}

ALMEIDA, C., 1999. Reforma do Estado e reforma de sistemas de saúde: Experiências internacionais e tendências de mudança. In: Política de Saúde e Inovação Institucional (N. R. Costa, org.), pp. 6998, Rio de Janeiro: Editora Fiocruz.

ARRETCHE, M. T., 1996. Mitos da descentralização: Mais democracia e eficiência nas políticas públicas? Revista Brasileira de Ciências Sociais, 31:4466.

COHN, A., 2000. As políticas sociais no governo FHC. Tempo Social, 11:183-198.

ELIAS, P. E. M., 1997. Reforma e contra-reforma na proteção à saúde. Lua Nova, 40/41:193-216.

FAVERET FILHO, P. \& OLIVEIRA, P. J., 1989. A Universalização Excludente: Reflexões sobre a Tendência do Sistema de Saúde. Rio de Janeiro: Instituto de Economia, Universidade Federal do Rio de Janeiro.

FIORI, J. L., 1993. Ajuste, transição e governabilidade: O enigma brasileiro. In: Desajuste Global e Modernização Conservadora (M. S. Tavares \& J. L. Fiori, org.), pp. 127-193, Rio de Janeiro: Editora Paz e Terra.

FITOUSSI, J. P. \& ROSANVALLON, P., 1996. Le Nouvel Âge des Inégalités. Paris: Éditions du Seuil.

FLEURY, S., 2000. Reshaping health care systems in Latin America: Toward fairness? In: Reshaping Health Care in Latin America. A Comparative Analysis of Health Care Reform in Argentina, Brazil and México (S. Fleury, S. Belmartino \& E. Baris, ed.), Ottawa: International Development Research Centre. <http://www.idrc.ca/books/ focus/923/s0c01.htm >.

HENRIQUES, R., 2000. Introdução. Desnaturalizar a desigualdade e erradicar a pobreza: Por um novo acordo social no Brasil. In: Desigualdade e Pobreza no Brasil (R. Henriques, org.), pp. 1-18, Rio de Janeiro: Instituto de Pesquisa Econômica Aplicada.
LAVINAS, L., 2000. Combinando compensatório e redistributivo: O desafio das políticas sociais no Brasil. In: Desigualdade e Pobreza no Brasil (R. Henriques, org.), pp. 503-520, Rio de Janeiro: Instituto de Pesquisa Econômica Aplicada.

NASCIMENTO, V., 2001. Interdependência e autonomia na gestão pública da saúde. Lua Nova, 52:2970.

OFFE, C., 1989. Trabalho: A categoria sociológica chave? In: Capitalismo Desorganizado (C. Offe, org.), pp. 167-197, São Paulo: Editora Brasiliense.

RAWLS, J., 1993, Uma Teoria da Justiça. Lisboa: Editorial Presença.

SALLUM, B., 1996, Labirintos - Dos Generais à Nova República. São Paulo: Editora Hucitec/Universidade de São Paulo.

SEN, A., 1993. O desenvolvimento como expansão de capacidades. Lua Nova, 28/29:313-333.

SEN, A., 2000. Desenvolvimento como Liberdade. São Paulo: Companhia das Letras.

SOUZA, C., 2001. Federalismo e gasto social no Brasil: Tensões e tendência. Lua Nova, 52:5-28.

TELLES, V. S., 1999. Direitos Sociais - Afinal do que se Trata? Belo Horizonte: Editora UFMG.

Recebido em 23 de maio de 2002

Versão final reapresentada em 17 de setembro de 2002 Aprovado em 30 de setembro de 2002 